\title{
A Lightweight Model for Gear Mesh Dynamics Incorporating Variable Mesh Stiffness
}

\author{
FOKAS Nikolaos ${ }^{1, a}$ \\ ${ }^{1}$ Psyche engineering systems and technologies BV, Koningin Juliana Plein 10, 2595 AA Den Haag, Netherlands
}

\begin{abstract}
Variable stiffness of the gear tooth mesh for a pair of spur gears is computed using an accurate lightweight mathematical formulation. This is used to simulate gear dynamic behavior. Gear eigenfrequencies are calculated for the SDOF system and correlated with gear physical properties and the effect of stiffness variation during a mesh cycle is studied.
\end{abstract}

\section{Introduction}

The study of gear vibration has traditionally treated problems such as the determination of the primary resonant speeds of given gear mechanisms, or calculating the corresponding load factors [1-5]. However these models are typically either too simplistic in terms of how stiffness is modelled, or employ complex FEA analysis that is resource intensive. In this paper a novel accurate and yet computationally lightweight SDOF model for gear dynamics is developed on the basis of recently developed analytical and numerical models for calculating gear geometry, contact and kinematics [6-13] and mechanical response of the elastic tooth mesh, in consideration of various tooth geometries [14-24].The implications of the varying tooth stiffness during a mesh cycle on the overall dynamic response are studied and a correlation is made between the gear properties and the tooth stiffness distribution based on the results of numerous simulations.

\section{Modelling}

The general dynamic equations governing the torsional behavior of a single gear pair are:

$$
\begin{aligned}
& J_{1} \dot{\boldsymbol{\omega}}_{1}+c_{1} \boldsymbol{\omega}_{1}=-\sum \overrightarrow{O_{1} A} \times\left(\mathbf{F}_{n}+\mathbf{F}_{s}\right)+\mathbf{T}_{1} \\
& J_{2} \dot{\boldsymbol{\omega}}_{2}+c_{2} \boldsymbol{\omega}_{2}=\sum \overrightarrow{O_{2} A} \times\left(\mathbf{F}_{n}+\mathbf{F}_{s}\right)+\mathbf{T}_{2}
\end{aligned}
$$

where $\mathrm{J}$ is the moment of inertia, $\omega$ is the angular velocity, $\mathrm{A}$ is the instantaneous mesh contact point, $\mathrm{O}$ is the gear centre of rotation, $\mathrm{Fn}$ is the mesh normal force,
Fs is the mesh friction force and $\mathrm{T}$ is the external torque acting on the gear shaft.

By introducing the stiffness coefficients $\mathrm{K}$ and friction torque coefficients $\mathrm{Fr}$ into the previous equations, we obtain:

$$
\begin{gathered}
J_{1} \ddot{\vartheta}_{1}+c_{1} \dot{\vartheta}_{1}=\left[ \pm \frac{1}{i_{12}} K+F r_{1}\right] \vartheta^{*} \pm \frac{c_{\vartheta}}{i_{12}} \frac{d}{d t} \vartheta^{*}+T_{1} \\
J_{2} \ddot{\vartheta}_{2}+c_{2} \dot{\vartheta}_{2}=\left[K+F r_{2}\right] \vartheta^{*}+c_{\vartheta} \frac{d}{d t} \vartheta^{*}+T_{2}
\end{gathered}
$$

where:

$$
\begin{gathered}
\vartheta^{*}=\left(\vartheta_{2}-\vartheta_{20}\right) \pm \frac{1}{i_{12}}\left(\vartheta_{1}-\vartheta_{10}\right)=\vartheta_{2} \pm \frac{1}{i_{12}} \vartheta_{1}-a \\
a=\vartheta_{20} \pm \frac{1}{i_{12}} \vartheta_{10} \\
\frac{d}{d t} \vartheta^{*}=\dot{\vartheta}_{2} \pm \frac{1}{i_{12}} \dot{\vartheta}_{1}
\end{gathered}
$$

where $K=K\left(\vartheta_{1}\right), F r_{1}=F r_{1}\left(\vartheta_{1}\right), F r_{2}=F r_{2}\left(\vartheta_{1}\right), \vartheta$ is the gear position, $\vartheta^{*}$ is the dynamic transmission error and the negative sign applies to internal gearing. The kinematics and contact geometry are calculated as per [6] and the stiffness and friction torque coefficients are calculated as per $[7,20,23]$ and shown in Fig. 1.

\footnotetext{
${ }^{\mathrm{a}}$ Corresponding author: $\underline{\operatorname{rtd} @ \text { psyx.eu }}$
} 


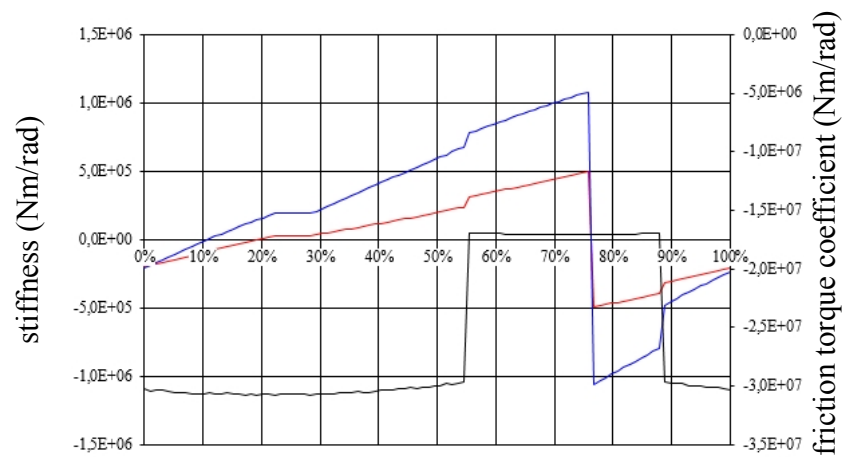

Figure 1. Calculated stiffness (black line) and friction torque coefficients (blue and red lines) at different $\%$ positions in the mesh cycle.

By substituting $\vartheta^{*}$ and $\frac{d}{d t} \vartheta^{*}$ and after a series of calculations, we obtain for the system of dynamic equations the eigenvalues:

$$
k= \pm j \sqrt{\left(\frac{1}{J_{1} i_{12}^{2}}+\frac{1}{J_{2}}\right)|K|}
$$

where $K<0$ and $j=\sqrt{-1}$. The torsional eigenfrequencies of the gear stage are then found as functions of $K$ :

$$
f_{e}=\frac{1}{2 \pi} \sqrt{\left(\frac{1}{J_{1} i_{12}^{2}}+\frac{1}{J_{2}}\right)|K|}
$$

For the purposes of this analysis let us consider steady operating conditions, i.e. conditions where the gear speed and the external loads are either constant or changing slowly. Assuming such conditions, it can be argued without significant error for a time interval spanning the execution of a few mesh cycles that:

$$
\vartheta_{1}=\omega_{1} t+\left.\vartheta\right|_{t=0}
$$

where $\omega_{1}$ is the mean angular velocity of gear 1 . Because the coefficients $K=K\left(\vartheta_{1}\right), F r_{1}=F r_{1}\left(\vartheta_{1}\right)$, $F r_{2}=F r_{2}\left(\vartheta_{1}\right)$ are all periodic in terms of $\vartheta_{1}$, with a period of $\frac{2 \pi}{z_{1}}$, Eq. (10) allows the previous coefficients to be formulated as $K=K(t), F r_{1}=F r_{1}(t)$, $F r_{2}=F r_{2}(t)$, which are also periodic in terms of $t$ with a period of $\frac{2 \pi}{\omega_{1} z_{1}}$. This stimulates a biased vibration of the gear stage, similar to a vibration produced by external periodic excitation. It follows that this vibration has a frequency $f_{z}=\frac{\omega_{1} z_{1}}{2 \pi}$, which is of course the tooth mesh frequency.

Looking at Fig. 1, which shows the calculated variation of the stiffness and friction torque coefficients, one can observe almost step-like changes in values of magnitudes $K, F r_{1}$ and $F r_{2}$, which occur near the highest and lowest points of single tooth contact and at the pitch point. During each mesh cycle these abrupt changes cause vibrations that are superimposed on the predominant vibration of frequency $f_{z}$. These vibrations manifest themselves in the eigenfrequencies of the gear pair and quickly tend to decay (as in Fig. 2). Similar eigenvibrations are also stimulated by external excitations, such as those which occur during start-up.

\section{Results and Discussion}

In Fig. 1 it can be readily observed that for the most part of the duration of a tooth pair mesh cycle pair stiffness $K$ takes values in two very narrow regions which may in fact be accurately represented by only two characteristic values $K_{u}$ (lower stiffness limit) and $K_{o}$ (upper stiffness limit) respectively. For a given gear material (in this case steel) each one of the two stiffness limits can be considered to be a function of $m$ (module), $z_{1}$ (number of pinion teeth), $i_{12}$ (gear pair transmission ratio) and $b_{t}$ (tooth width), hence:

$$
K_{u, o}=f\left(m, z_{1}, i_{12}, b_{t}\right)
$$

With the application of Eq. (11) on several geometries it is concluded that:

$$
K_{u, o}=b_{t} m^{2}\left[c_{1}\left(z_{1}\right) i_{12}+c_{0}\left(z_{1}\right)\right]
$$

where functions $c_{0}$ and $c_{1}$ are extracted as statistical regressions.

After completing a series of simulations for gear pair geometries within the specifications:

$$
\begin{aligned}
& 18 \leq z_{1} \leq 30 \\
& i_{12} \leq 10.0 \\
& a_{o}=20^{\circ}
\end{aligned}
$$

the final equations for $K_{u}$ and $K_{o}$ are extracted as follows:

$$
K_{u}=100 m^{2} b_{t}\left[\left(0.0100 z_{1}^{2.1496}\right) i_{12}-0.1747 z_{1}+1.4221\right]
$$

$(\mathrm{Nm} / \mathrm{rad})$

$$
K_{o}=100 m^{2} b_{t}\left[\left(0.0178 z_{1}^{2.1561}\right) i_{12}-0.0938 z_{1}+0.6771\right]
$$

\section{$(\mathrm{Nm} / \mathrm{rad})$}

where $m$ and $b_{t}$ are given in $\mathrm{mm}$. 

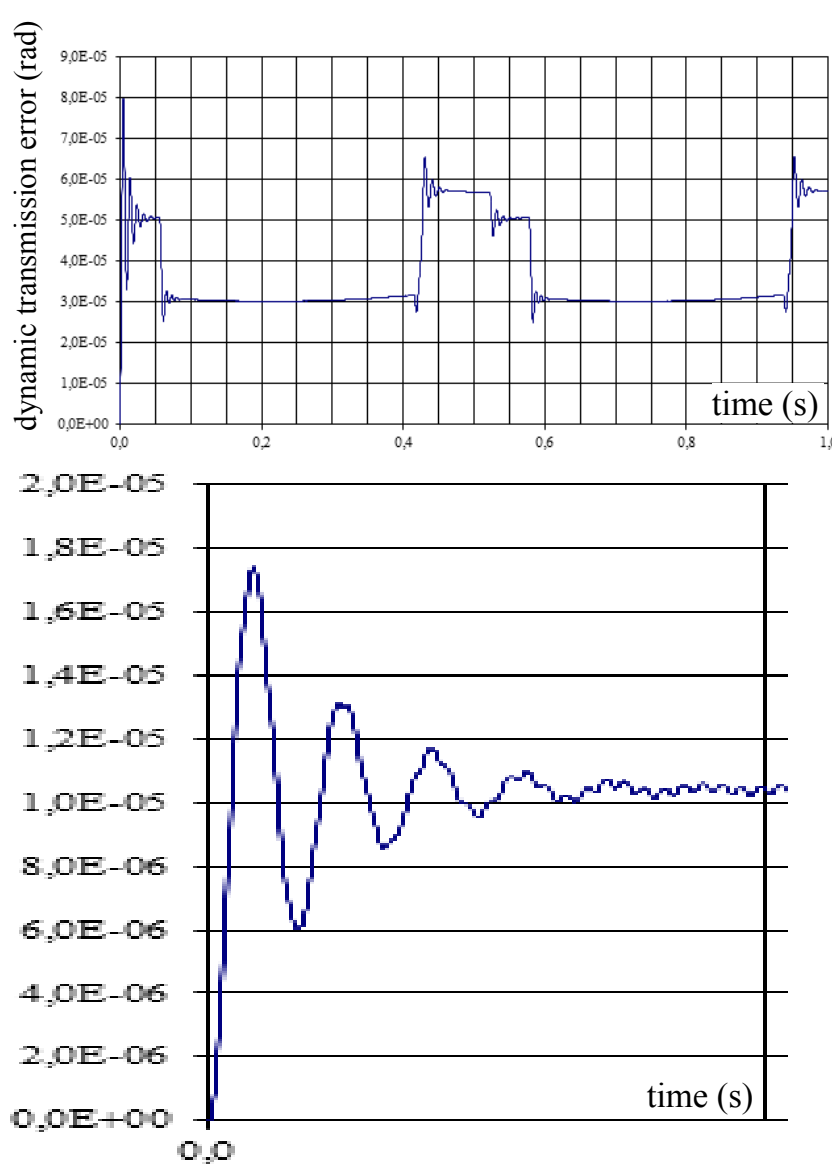

Figure 2. Simulated dynamic transmission error during low speed rotation vs time (s) (case A, left) and after torsional impulse at zero rotational speed $(0.05 \mathrm{~s}$ interval shown), showing vibration attenuation (case $\mathrm{B}$, right).

For a single stage of involute spur gears in compliance with the specifications used previously for the stiffness coefficient limits regressions the limits $f_{e, u}$ and $f_{e, o}$ are determined by means of Eq. (9) and Eqs. (16)-(17) as:

$$
\begin{aligned}
& f_{e, u}=\frac{1}{2 \pi} \sqrt{\left(\frac{1}{J_{1} i_{12}^{2}}+\frac{1}{J_{2}}\right) K_{u}}(\mathrm{~Hz}) \\
& f_{e, o}=\frac{1}{2 \pi} \sqrt{\left(\frac{1}{J_{1} i_{12}^{2}}+\frac{1}{J_{2}}\right) K_{o}}(\mathrm{~Hz})
\end{aligned}
$$

Two test cases A, B were simulated for a pair of standard involute spur gears with a transmission ratio of 23/50 and the results shown in Fig. 2. In both cases the predominant vibration is in frequency $f_{z}=\frac{\omega_{1} z_{1}}{2 \pi}$, which in case $\mathrm{A}$ is $1.917 \mathrm{~Hz}$ and in case $\mathrm{B}$ is $575 \mathrm{~Hz}$. Immediately after $t=0$ follows a dampened transitional response in a system eigenfrequency, which results from the sudden application of the external load on the rotating gears.

Measurements on the data of Fig. 2 reveal the eigenfrequencies $f_{1}=92 \pm 4 \mathrm{~Hz}, f_{2}=100 \pm 5 \mathrm{~Hz}$ and $f_{3}=130_{-8}^{+9} \mathrm{~Hz}$. Equations (18)-(19) on the other hand yield the values $f_{e, u}=94.1 \mathrm{~Hz}$ and $f_{e, o}=133.7 \mathrm{~Hz}$, which are evidently in complete agreement with the previous measurements, thus confirming the preceding theoretical analysis.

Cases A and B in Fig. 2, besides the main vibration component in tooth meshing frequency, also reveal an initial eigenvibration in frequency $f_{4}=107_{-7}^{+8} \mathrm{~Hz}$. As, however, the tooth meshing frequency $f_{z}=575 \mathrm{~Hz}$ is far higher than the upper eigenfrequency limit $f_{e, o}=133.7 \mathrm{~Hz}$, the previously established eigenfrequencies $f_{1}, f_{2}$ and $f_{3}$ no longer have a visible influence on the dynamic response.

\section{Conclusion}

A SDOF torsional model was presented for the simulation of gear dynamics, using an accurate formulation for mesh contact kinematics and variable mesh stiffness. Simulation results were analysed, showing the influence of the stiffness on the resulting vibrations for two test cases.

\section{References}

1. Wang J., and Howard I.: Journal of Mechanical Engineering Science, Vol. 218(1) (2004), pp. 131142

2. Liou C. H., Lin H. H., Oswald F. B., and Townsend D. P.: Journal of Mechanical Design, Vol. 118(3) (1996), pp. 439-443

3. Spitas C., and Spitas V.: Journal of Multi-Body Dynamics, Vol. 220(4) (2006), pp. 273-282

4. Karimpour M., Dearn K.D., and Walton D.: Journal of Materials: Design and Applications, Vol. 224(3) (2010), pp. 101-115

5. Tamminana V.K., Kahraman A., and Vijayakar S.: Journal of Mechanical Design, Vol. 129(1) (2006), pp. 75-84

6. Spitas C., and Spitas V.: Mechanism and Machine Theory, Vol. 46(7) (2011), pp. 869-879

7. Spitas C.: Journal of Sound and Vibration, Vol. 324(1-2) (2009), pp. 297-316

8. Spitas C., and Spitas V.: Applied Mathematical Modelling, Vol. 32(10) (2008), pp. 2162-2171

9. Litvin F.L., Gonzalez-Perez I., Fuentes A., Hayasaka K., and Yukishima K.: Mathematical and Computer Modelling, Vol. 42(9-10) (2005), pp. 1063-1078

10. Spitas C., Costopoulos T., and Spitas V.: Inverse Problems in Science and Engineering, Vol. 16(2) (2007), pp. 171-186

11. Spitas V., Costopoulos T., and Spitas C.: Mechanism and Machine Theory, Vol. 42(6) (2007), pp. 751-762

12. Litvin F.L., Fuentes A., Gonzalez-Perez I., Carnevali L., Kawasaki K., Handschuh R.F.: Computer Methods in Applied Mechanics and Engineering, Vol. 192 (2003), pp. 3619-3655 
13. Spitas C., and Spitas V.: Journal of Mechanical Engineering Science, Vol. 220 (8) (2006), pp. 13051313

14. Arafa M.H., and Megahed M.M.: Journal of Mechanical Engineering Science, Vol. 213 (1999), pp. 569-579

15. Spitas C., Spitas V., Amani A., and Rajabalinejad M.: Acta Mechanica, Vol. 225(2) (2014), pp. 361371

16. Chaari F., Takhfakh T., and Haddar M.: European Journal of Mechanics - A/Solids, Vol. 28(3) (2009), pp. 461-468

17. Spitas V., and Spitas C.: Mechanics Based Design of Structures and Machines, Vol. 35(2) (2007), pp. 163-178

18. Spitas C., and Spitas V.: Mechanics Based Design of Structures and Machines, Vol. 36(2) (2008), 189211
19. Spitas V., and Spitas C.: Acta Mechanica, Vol. 193(1-2) (2007), pp. 113-126

20. Spitas C., and Spitas V.: Mechanics Based Design of Structures and Machines, Vol. 35(1) (2007), pp. 59-73

21. Pimsarn M., and Kazerounian K.: Mechanism and Machine Theory, Vol. 37(8) (2002), pp. 769-786

22. Spitas V., and Spitas C.: Journal of Mechanical Engineering Science, Vol. 221 (2006), pp. 479-488

23. Amarnath A., Sujatha C., and Swarnamani S.: Tribology International, Vol. 42(2) (2009), pp. 340352

24. Munro R.G., Palmer D., and Morrish L.: Journal of Mechanical Engineering Science, Vol. 215(7) (2001)

pp.

793-803 